\title{
Modelling job crafting behaviours: Implications for work engagement
}

Arnold B Bakker, Alfredo Rodríguez Muñoz and Ana I Sanz Vergel

\begin{abstract}
In this study among 206 employees (103 dyads), we followed the job demandsresources approach of job crafting to investigate whether proactively changing one's work environment influences employee's (actor's) own and colleague s (partner's) work engagement. Using social cognitive theory, we hypothesized that employees would imitate each other's job crafting behaviours, and therefore influence each other's work engagement. Results showed that the crafting of social and structural job resources, and the crafting of challenge job demands was positively related to own work engagement, whereas decreasing hindrance job demands was unrelated to own engagement. As predicted, results showed a reciprocal relationship between dyad members' job crafting behaviours - each of the actor's job crafting behaviours was positively related to the partner's job crafting behaviours. Finally, employee's job crafting was related to colleague's work engagement through colleague's job crafting, suggesting a modelling process.
\end{abstract}

\section{Keywords}

Actor-partner interdependence model; Job crafting; Proactive behaviour; Social cognitive theory; Work engagement 
Traditional job design theories, like job characteristics theory (Hackman \& Oldham, 1980) and the interdisciplinary approach to job design (Campion, 1988), propose that employees can be motivated through the design of their job. However, since employees working in contemporary organizations likely have at least some latitude to modify their jobs (Oldham \& Hackman, 2010), there is increasing interest in the way employees influence or shape their own jobs. Wrzesniewski and Dutton (2001) refer to this influence as job crafting, defined as "the actions employees take to shape, mold, and redefine their jobs" (p.180). Job crafting may include changing what one does as a part of the job, how one approaches work, or how one interacts with others. Job crafting can also take the form of increasing one's own job challenges and job resources, as well as decreasing one's hindrance job demands (Tims, Bakker, \& Derks, 2012).

There is accumulating evidence that job crafting has a positive impact on job satisfaction, work engagement, and job performance (Bakker, Tims, \& Derks, 2012; Laurence, 2010; Lyons, 2008; Petrou, Demerouti, Peeters, Schaufeli, \& Hetland, 2012; Tims, Bakker \& Derks, 2013). In the present study, we aim to expand this literature by investigating the impact of job crafting on one's direct colleague. We will use social cognitive theory to argue that employees may imitate each other's job crafting behaviours, and influence each other's work engagement. With our study among dyads of employees, we may contribute to the field in two different ways. First, using Tims et al.'s (2012) conceptualization of job crafting, we examine how different job crafting behaviours may be modelled among co-workers. Evidence for the modelling of job crafting would confirm the interpersonal consequences of proactive behaviour at work. Second, we investigate whether employee job crafting can influence co-worker's work engagement - an affective, motivational state consisting of vigour, dedication, and absorption (Bakker, 2011). Previous research has indicated that work engagement is 
linked to important organizational outcomes (Christian, Garza, \& Slaughter, 2011), thus emphasizing the relevance of this outcome. We use the Actor-Partner Interdependence Model (APIM; Kashy \& Kenny, 2000) as a statistical technique to investigate reciprocal effects between the members of the dyads.

\section{Theoretical background}

People are not "passive recipients of environmental presses" (Buss, 1987, p. 1220). Instead, they actively influence their own environment, with the aim to align the environment with their preferences and abilities (Tims \& Bakker, 2010), and to change the meaning of their work (Wrzesniewski \& Dutton, 2001). The latter authors introduced the concept of "job crafting" to refer to this process of employees shaping their jobs. They proposed that job crafting can take the form of physical and cognitive changes individuals make in their task or relational boundaries. In this approach, physical changes refer to changes in the form, scope or number of job tasks, whereas cognitive changes refer to changes in how one perceives the job. Changes in one's relational boundaries refer to changing the interactions and relationships individuals have with others at work

Wrzesniewski and Dutton's (2001) definition of job crafting is restricted to those changes that employees may make in their specific work tasks, relationships at work, and cognitions about work. Some recent studies have suggested that job crafting may take other forms as well. For example, Lyons (2008) found that the salespersons in his study engaged in self-initiated skill development. In another study, Laurence (2010) showed that job crafting can take the form of contraction - job crafting behaviours that aim to decrease stimulation or reduce the complexity of the task or relational environment. Finally, research by Petrou et al. (2012) showed that employees engage in 
job crafting by asking for feedback and social support when needed, and by actively searching for job challenges.

Results from these studies provide evidence for job crafting as private behaviour. However, Wrzesniewski and Dutton (2001) point out that the opportunity to perform this type of behaviours as well as the effects of job crafting may depend on others - including colleagues and supervisors. Indeed, there is evidence that job crafting is not merely and individual behaviour since groups of individuals may craft their jobs to meet shared objectives (Leana, Appelbaum, \& Shevchuk, 2009). The latter authors use the term "collaborative job crafting" to refer to workers who together customize how their work is organized and enacted (p. 1170). In a recent study, Tims, Bakker, Derks and Van Rhenen (2013) also found evidence for team-level job crafting, and showed how team job crafting influenced individual performance through individual work engagement.

\section{The Job Demands-Resources model approach to job crafting}

In the present study, we follow the Job Demands-Resources model (JD-R) approach to job crafting (Tims \& Bakker, 2010; Tims et al., 2012), because we are interested in how employee-driven changes in job characteristics contribute to work engagement. JD-R theory (Bakker \& Demerouti, 2008, 2014) proposes that all job characteristics can be categorized as either job demands or job resources. Job demands refer to those physical, social or organizational aspects of the job that require sustained effort at the physical or cognitive levels. Job resources are defined as aspects of the job that may be helpful to achieve work goals, to reduce demands or to stimulate personal growth. According to the theory, job demands and job resources initiate two different, simultaneous processes, with chronic high job demands leading to strain, health 
problems and absenteeism ('health impairment process'), and high job resources leading to positive organizational outcomes ('motivational process') (Demerouti, Bakker, Nachreiner, \& Schaufeli, 2001). Job demands and resources also interact and their combination explains additional variance in strain and work engagement, and indirectly in performance. Specifically, job resources buffer the undesirable impact of job demands on strain, whereas challenge job demands 'boost' the positive impact of job resources on work engagement (Bakker \& Demerouti, 2014). By framing job crafting in terms of job demands and job resources, we are able to capture a wide variety of aspects (i.e., job characteristics) that employees may proactively change in their jobs.

On the basis of JD-R theory, Tims et al. (2012) empirically distinguished four dimensions of job crafting, namely: (1) increasing structural job resources, (2) increasing social job resources, (3) increasing challenge job demands, and (4) decreasing hindrance job demands. These dimensions refer to actual behaviours, that is, what people actually do to change or shape their jobs. Increasing structural resources refers to proactively mobilizing job resources such as opportunities for development, autonomy, or skill variety, whereas increasing social resources refers to seeking social support, supervisory coaching, or performance feedback. The two other dimensions of job crafting, increasing challenge demands and decreasing hindrance demands are based on extensions of the JD-R model, differentiating between hindrance and challenge demands.

According to Crawford, LePine, and Rich (2010), challenge job demands are appraised as demands that have the potential to promote mastery and future gains, whereas hindrance job demands are perceived as constraints that block progress. Examples of challenges demands are work pressure or job complexity, while hindrance demands include role conflict or role ambiguity. These authors found that challenge 
demands were positively related to engagement, whereas hindrance demands were negatively related to engagement. Van den Broeck, De Cuyper, De Witte, and Vansteenkiste (2010) also used this differentiation between types of job demands and found that hindrances were negatively related to vigour, whereas challenges were positively related to vigour.

According to Tims et al. (2012), particularly the dimensions of increasing challenge job demands and increasing social and structural resources will lead to work engagement - i.e. high levels of energy, strong dedication, and full concentration on one's work (Bakker, 2011). One important reason for this is that a working environment with challenge job demands and job resources satisfies basic psychological needs, such as the needs for competence, relatedness, and autonomy (Van den Broeck, Vansteenkiste, De Witte, \& Lens, 2008). For example, increasing structural resources and challenging job demands involves trying to learn new things, deciding how to do things, as well as being involved in new projects. Through these behaviours, people can fulfil their needs for competence and autonomy. In the case of increasing social resources, by asking for feedback and advice, people may receive support of others and fulfil their need for relatedness. Therefore, we predict:

Hypothesis 1. Job crafting in the form of increasing challenge job demands and increasing job resources is positively related to own work engagement.

Furthermore, the literature shows that reducing hindrance job demands is negatively related to work engagement, and positively related to burnout (e.g., Tims et al., 2012). Originally, Tims and Bakker (2010) argued that reducing hindrance demands would be positively related to well-being and job satisfaction, because this form of job 
crafting would improve the fit between the employee and the work environment. Also, since there is meta-analytic evidence for a negative relationship between hindrance job demands and work engagement (Crawford et al., 2010), one would theoretically expect a positive link between job crafting in the form of reducing hindrance demands and work engagement. However, the negative link between reducing hindrance demands and engagement reported in the literature is consistent with a central claim in the JD-R model regarding independent and dual processes. Accordingly (hindrance) job demands have a unique, positive effect on burnout (Demerouti et al., 2011), whereas job resources are the most important drivers of work engagement. Job demands foster burnout (particularly exhaustion), because they cost effort and instigate a healthimpairment process. This implies that reducing hindrance job demands does not help to improve engagement - there is nothing challenging and no resources have been gained after reducing hindrance job demands. Moreover, a recent study has suggested that reducing job demands may in itself be effortful and undermine work engagement (Oerlemans \& Bakker, 2013). Consistent with the latter finding, in a quantitative diary study among a heterogeneous group of employees, Petrou et al. (2012) found a negative relationship between decreasing hindering demands and daily work engagement. Similarly, in their longitudinal survey study among police officers, Petrou, Demerouti and Schaufeli (in press) found that reducing demands was negatively related to work engagement and adaptation to change one year later. On the basis of this literature review, we propose that:

Hypothesis 2: Job crafting in the form of decreasing hindrance job demands is negatively related to own work engagement. 


\section{Modelling of job crafting}

In the present study, we argue that job crafting will also influence the job crafting of others in one's work environment, and indirectly others' work engagement. The study will be conducted among dyads of co-workers to investigate whether there is a bidirectional relationship between the job crafting behaviours of both members of the dyad. We will use the Actor-Partner Interdependence Model (APIM; Kashy \& Kenny, 2000; see Method for details) to investigate whether the actor's job crafting is related to the partner's work engagement, through partner's job crafting.

Bandura's $(1977,1997)$ social cognitive theory (SCT) posits that people learn from one another, via observation, imitation, and modelling. He argued that "Fortunately, most human behaviour is learned observationally through modelling: from observing others, one forms an idea of how new behaviours are performed, and on later occasions this coded information serves as a guide for action." (Bandura, 1977, p. 22). By learning from example what to do before performing any behaviour, people can prevent needless errors. According to SCT, a person can be motivated to perform certain behaviours by observing a model's behaviour and the consequences of that behaviour. By observing their co-workers, employees can infer which behaviours are appropriate and rewarding in the workplace. This motivates the same behaviour. By observing the actions and the responses to these actions of others, one can also induce how one is expected to behave, and find out what the norms are (Postmes, Spears, \& Lea, 2000). Thus, a person learns about the relationship between certain behaviours and consequences, and bases his or her expectations on this.

Model characteristics (e.g., similarity, status, success) are taken into account to judge whether the behaviour is appropriate to imitate and whether it will lead to valued outcomes. Employees working in the same team or department may perceive each other 
to be similar, because people are attracted to, selected by, and remain in organizations that contain similar others (Schneider, 1987). Thus, when people see a co-worker engage in job crafting activities, they may engage in this behaviour too while working on their own tasks. The presence of a role model (i.e., co-worker) who crafts may have a substantial impact on the crafting of an individual. Zhou (2003), for example, showed that when employees worked with creative co-workers, they were more creative themselves. Furthermore, in a daily diary study among 62 dyads of employees, Bakker and Xanthopoulou (2009) found that on days that there were ample opportunities to model the other (i.e. when the frequency of interaction and communication was high), members of the dyad influenced each other's job performance, through work engagement.

According to Bandura (1997), the influence of modelling is higher when individuals see the models similar to them in characteristics such as age, gender or status, or in the type of problems with which they cope. Further, Brass and Burkhardt (1993) have stressed that co-workers shape employees' behaviours by offering "cues". Employees observe the cues offered by the co-workers and align their actions based on that. If the behaviours lead to success, it is more likely that employees decide to imitate those successful behaviours (i.e., job crafting). For example, if an employee asks the supervisor to coach him/her and as result he/she performs the work better, the colleague may learn that this is a good strategy to increase performance. According to Salancik and Pfeffer (1978) one of the main mechanisms through which co-workers may affect employees' behaviours is the role modelling mechanism that fosters employees' vicarious learning. On the basis of this literature, we predict: 
Hypothesis 3: There will be a bidirectional relationship between the actor's job crafting behaviours [(a) increasing structural job resources, (b) increasing social job resources, (c) increasing challenge job demands, and (d) decreasing hindrance job demands], and the partner's symmetrical job crafting behaviours.

Finally, combining Hypotheses 1-3, we expect that actor job crafting will influence partner work engagement via the modelling of job crafting. This relationship may be direct, because the job challenges and resources mobilized by the actor will most likely result in a more favourable environment for the actor and the partner. Indeed, as suggested by Wrzesniewski and Dutton (2001) job crafting alters the social environment in which the employee works. However, we are interested in examining a mediating process, which is the combination of the three previous hypotheses.

Therefore, we predict that actor job crafting influences partner work engagement through partner job crafting. Since the behaviours of the actor will be modelled, we expect that the partner will craft a more motivating and more stimulating work environment for him or herself, with higher challenging job demands and higher job resources, whereas the work will be less motivating with the decrease of hindering job demands, which will be negatively related to work engagement (cf. Tims et al., 2013). We propose these final hypotheses:

Hypothesis 4a: Actor's job crafting in the form of increasing challenge job demands and job resources is positively related to partner's work engagement through partner's job crafting in the form of increasing challenge job demands and job resources (mediation hypothesis). 
Hypothesis 4b: Actor's job crafting in the form of hindrance job demands is negatively related to partner's work engagement through partner's job crafting in the form of hindrance job demands (mediation hypothesis).

\section{Method}

\section{Participants and procedure}

The present study was conducted among employees from seven different companies in Poland, Romania, Lithuania, and The Netherlands. Employees were contacted by three master students and invited to participate in this study. Both companies and individuals were contacted (through phone and e-mail) and invited to participate in this study. In order to attract a sufficient number of participants, announcements about the study were also posted on the internet - through different forums, social and professional networks, discussion boards, etc. Offering the participants a chance to win a portable media player encouraged participation in the study. Individuals who decided to participate were kindly requested to ask a co-worker to participate as well. To guarantee confidentiality, all responses of the dyad members were linked by means of anonymous codes provided by the researchers. The questionnaire was set up on an online survey platform. The link was sent to 590 individuals, and 215 complete questionnaires were returned (36.4\% response rate). After excluding participants who did not form a dyad, a total of 206 valid questionnaires were kept, resulting in 103 dyads. Most participants completed the questionnaire in English, although we also provided Polish, Romanian, and Lithuanian versions in case the participants wanted to fill out the items in their own language. The vast majority of the participants indicated that they mastered the English language well (33\%) or very well $(62 \%)$. 
The final study sample consisted of 90 men (43.7\%) and 116 women (56.3\%). The average age of the participants was 30.75 years $(\mathrm{SD}=6.42)$ and their mean organizational tenure was 5.01 years $(\mathrm{SD}=4.09)$. The majority of the sample held a master's degree $(59.2 \%)$. They had one of twelve different nationalities; $32 \%$ were Polish, 28.2\% Romanian, 19.9\% Lithuanian, $12.6 \%$ Dutch, and $7.3 \%$ had other nationalities (British, French, Ukrainian, Jordanian, Mexican, Peruvian, Vietnamese, Australian). Participants worked in a broad range of sectors, including advertising/communications (16.5\%), finances (17.5\%), business services/consultancy (13.6\%), entertainment (9.7\%), architecture and design (5.8\%), education (4.9\%), IT $(4.9 \%)$, retail $(4.9 \%)$, or other $(22.2 \%)$.

\section{Measures}

Job crafting was measured with the job crafting scale developed by Tims et al. (2012). The dimensions of the scale are Increasing structural job resources (e.g., "I try to learn new things at work"; $\alpha=.83$ ), Increasing social job resources (e.g., "I ask others for feedback on my job performance; $\alpha=.80$ ), Increasing challenge job demands (e.g., "When an interesting project comes along, I offer myself proactively as project coworker"; $\alpha=.81$ ), and Decreasing hindrance job demands (e.g., "I make sure that my work is mentally less intense"; $\alpha=.77)$. Each dimension of the scale includes five items, except Decreasing hindrance job demands which consists of six items. Items were rated on a 5-point scale, ranging from 1 ("never") to 5 ("very often"). Confirmatory factor analysis (CFA) showed that a four-factor model of job crafting better represented the factor structure of the scale, and fit significantly better to the data as compared to a one-factor model $\left(\Delta \chi^{2}(5)=701.3, p<.001\right)$, a two-factor model where the two job demands and the two job resources were combined in two general 
factors $\left(\Delta \chi^{2}(4)=592.2, p<.001\right)$, and a three-factor model in which increasing structural and social job resources were modelled as one factor $\left(\Delta \chi^{2}(3)=280.0, p<\right.$ .001 ), and a three-factor model where the two job resources were modelled as two separate latent factors and the two job demands were indicative of one general factor $\left(\Delta \chi^{2}(3)=147.49, p<.001\right)$. The four-factor model showed a reasonable, though not perfect fit to the data, $\chi^{2}(175)=457.87, \mathrm{CFI}=.90, \mathrm{TLI}=.89, \mathrm{RMSEA}=.06$.

Work engagement was assessed with the 9-item version of the Utrecht Work Engagement Scale (Schaufeli, Bakker, \& Salanova, 2006). This version includes three items for each engagement dimension: vigour (e.g., "At my work, I feel bursting with energy"), dedication (e.g., "I am enthusiastic about my job"), and absorption (e.g., "I am immersed in my work"). Items were scored on a seven-point rating scale ranging from 0 ("never") to 6 ("always"). Since confirmatory factor analyses have shown that the three dimensions are closely related (e.g., Schaufeli et al., 2006), we have decided to use one overall index for work engagement. Cronbach's $\alpha$ was .93.

Other variables. As control variables, we included gender, age, educational level, marital status, number of children, job status, organizational tenure, and number of hours actually worked per week.

\section{Data analysis}

Our data set is composed of two levels: the dyad-level (Level 2; $N=103$ dyads) and the person-level (Level 1; $N=206$ participants), with individuals nested within dyads. To test the hypotheses, we conducted multilevel analyses with the MLwiN program (Rasbash, Browne, Healy, Cameron, \& Charlton, 2002). Statistical power 
analyses for two-level models were conducted with the optimal design software (Spybrook, Raudenbush, Liu, Congdon, \& Martínez, 2008). The analyses resulted in values higher than .80 , suggesting adequate power for our analyses. Independent variables were person-mean centred to avoid problems of multicollinearity (Kashy \& Kenny, 2000), whereas gender was centred to the grand-mean.

We analysed our data following the actor-partner interdependence model (APIM; Cook, \& Kenny, 2005; Kenny, Kashy, \& Cook, 2006). This approach has been used in previous studies with a similar research design with dyads of employees (e.g., Bakker \& Xanthopoulou, 2009). When data is collected from both members of a dyad, it cannot be treated as independent from one another (Kashy \& Kenny, 2000). Thus, APIM was designed to deal with violations of statistical independence, as well as for investigating dyadic effects in close relationships. Specifically, APIM allows examining how an individual's predictor variable simultaneously and independently relates to his or her own criterion variable (actor effect), and to his or her partner's criterion variable (partner effect). In APIM models, the partner effect allows to test the mutual (i.e., reciprocal) influence between the members of the dyad (Kenny et al., 2006). In the current study, the relation of job crafting behaviours between actor and partner is tested simultaneously with the relation from the partner to the actor (bidirectional relationship). It's important to underline that APIM models include information of the two members of the dyad simultaneously. Moreover, as we were not interested in specific partner relationships (e.g., male vs. female), the members of the dyad were treated as indistinguishable. Thus, as suggested earlier, each member could be considered either as the actor or as the partner in the hypothesized relationships. 


\section{Results}

Preliminary analyses

The means, standard deviations, and correlations are presented in Table 1. The pattern of correlations was in the expected direction. Demographic variables were inconsistently related or unrelated to the study variables. Only participants' gender was positively related to both actor's $(r=.14, p<.05)$ and partner's work engagement ( $r=$ $.22, p<.01)$. Women scored higher on work engagement than men. Therefore, gender was used as covariate in all further analyses.

Before testing our hypotheses, we examined the variability of the scores on all variables by calculating the intraclass correlations with the intercept-only model. The intraclass correlation is the proportion of group-level variance compared to the total variance (Hox, 2002, p. 15). In our study, the intraclass correlation indicates the proportion of variance that can be explained due to differences between dyads and between persons. The results showed that $40.2 \%$ of the variance in work engagement could be attributed to between-dyad variations, whereas $59.8 \%$ of the variance was due to between-person variations. Results regarding Increasing Structural Job Resources indicated that $35.6 \%$ of the variance could be attributed to between-dyad variations, whereas $64.4 \%$ of the variance was due to between-person variations. In the case of Increasing Social Job Resources, results showed that $30.7 \%$ of the variance could be attributed to between-dyad variations, whereas $69.3 \%$ of the variance was due to between-person variations. Results concerning Increasing Challenge Job Demands showed that $45.1 \%$ of the variance could be attributed to between-dyad variations, whereas $54.9 \%$ of the variance was due to between-person variations. Finally, regarding Decreasing Hindrance Job Demands, $51.1 \%$ of the variance could be attributed to between-dyad variations, whereas $48.9 \%$ of the variance was due to between-person 
variations. These results clearly support the use of multilevel modelling, since the total variance is explained by differences between persons (Level 1) and dyads (Level 2).

\section{Hypothesis testing}

To test our study hypotheses, we examined a series of nested models. In the Null Model, we included the intercept as the only predictor. In Model 1, we included the person-level control variable (gender). In Model 2, we entered the four job crafting behaviours (dimensions) of the actor. Finally, in Model 3, we entered the four job crafting behaviours of the partner. The differences of the deviances of two subsequent models follow a chi-square distribution and indicate whether the additional explained variance is significant. Results showed that Model 3 showed a better fit to the data than Model 2 (difference of $-2 \mathrm{X} \log =88.05, \mathrm{df}=4, p<.001$ ), and thus also a better fit than Model 1 (difference of $-2 \times \log =103.96$, $\mathrm{df}=5, p<.001$ ), and the Null Model (difference of $-2 \times \log =104.93, \mathrm{df}=6, p<.001$ ).

Table 2 presents unstandardized estimates, standard errors, and t-values for all predictors. Hypothesis 1 stated that job crafting, specifically increasing challenge job demands and job resources, would be positively related to own work engagement. The results partially support Hypothesis 1, since partner's increasing challenge job demands $(t=3.77, p<.01)$ and increasing structural job resources $(t=6.98, p<.01)$ were positively related to partner's work engagement. However, partner's increasing social job resources $(t=0.87, p>.05)$ was not significantly related to partner's work engagement.

Hypothesis 2 suggested that decreasing hindrance job demands would be negatively related to work engagement. The results do not support this hypothesis, since partner's decreasing hindrance job demands was not significantly related to partner's 
work engagement $(t=0.13, p>.05)$. Note that the 'partner' in this case refers to the individual employee - it is an intra-personal effect.

Hypothesis 3 suggested that there would be bidirectional direction of job crafting between both members. Results showed a bidirectional relationship between all job crafting dimensions: actor's and partner's increasing structural job resources $(t=5.47, p$ $<.001)$, actor's and partner's increasing social job resources $(t=5.34, p<.001)$, actor's and partner's increasing challenge job demands $(t=7.30, p<.001)$, and actor's and partner's decreasing hindrance job demands $(t=8.53, p<.001)$. These findings support Hypothesis 3.

It is worth mentioning that additional analyses showed an asymmetric relationship between some of the different dimensions of job crafting. More specifically, we found a direct impact of actor's increasing challenging demands on partner's increasing structural resources $(t=2.88, p<.01)$ and social resources $(t=$ $2.99, p<.01)$. Thus, asymmetric relationships also seem to exist between the actor's and partner's job crafting dimensions.

Finally, Hypothesis 4a and 4b suggested that actor's job crafting would have a positive effect on partner's work engagement through partner's job crafting. The three conditions that should be met in order to support this mediation hypothesis are: (a) actor's job crafting should be positively related to partner's job crafting; (b) partner's job crafting should be positively related to partner's work engagement, and (c) after the inclusion of the mediator (partner's job crafting), the previously significant relationship between actor's job crafting and partner's work engagement turns into non-significance (full mediation), or becomes significantly weaker (partial mediation; Mathieu \& Taylor, 2006). We tested this mediation requirement for each job crafting dimension separately. 
Hypothesis 1 and 2 already supported the first two requirements, but only for increasing challenge job demands and increasing structural job resources. Regarding the third condition, results showed that the effect of actor's increasing challenge job demands on partner's work engagement became non-significant when partner's increasing challenge job demands was added to the model $(t=0.56, p>.05)$. The Sobel (1982) test showed that this reduction was significant $(z=3.35, p<.001)$. Similarly, the effect of actor's increasing structural job resources on partner's work engagement became non-significant when partner's increasing structural job resources was added to the model $(t=0.67, p>.05)$. Again, the Sobel test showed that this reduction was significant $(z=4.31, p<.001)$. Additionally, results showed that actor's increasing social job resources $(t=0.31, p>.05)$ was not significantly related to partner's work engagement. Taken together, these findings partially support hypothesis 4a by showing that full mediation exists for increasing challenge job demands and increasing structural job resources. Regarding the final job crafting dimension, results showed that actor's decreasing hindrance job demands had a direct, negative relationship with partner's work engagement $(t=-2.37, p<.01)$. However, actor's decreasing hindrance job demands did not play a mediating role $(z=1.33, p>.05)$. Thus, Hypothesis $4 \mathrm{~b}$ is rejected.

\section{Discussion}

The present study suggests that employees imitate each other's job crafting behaviours and indirectly influence each other's work engagement, signalling that proactive behaviour at work has important interpersonal consequences. These findings are consistent with Bandura's $(1977,1997)$ social cognitive theory and Job DemandsResources theory (Bakker \& Demerouti, 2008, 2014). Our results indicate that the 
crafting of job demands and job resources is related to one's own and one's colleague's levels of vigor, dedication, and absorption, although not all job crafting behaviours had the same effect. Below we discuss the most important contributions of the study in more detail.

\section{Theoretical contributions}

The first contribution of the present study is that it offers evidence for the hypothesis that employees craft their own work environment, and that their direct colleagues model this behaviour. Thus, when employees craft their work environment, by asking for support or feedback, or by trying to learn new things at work, their colleagues are likely to craft their environment in a similar way. These findings are consistent with social learning theory. Accordingly, people are inclined to observe and model the behaviours, attitudes, and emotional reactions of others (Bandura, 1977, 1997). By observing colleagues in the workplace, employees can infer which behaviours are most appropriate and effective. The job crafting of one employee may stimulate his or her colleagues' job crafting by focusing the attention on those characteristics of work that may be susceptible of being modified. Our findings are consistent with studies that have examined the modelling of other work behaviours, including creativity (Zhou, 2003), and emotional labour (Sanz-Vergel, RodríguezMuñoz, Bakker, \& Demerouti, 2012).

Previous research had provided evidence for the idea that colleagues can see the job crafting behaviour of each other; Tims and her colleagues (2012) found a positive correlation between self- and colleague-ratings of job crafting. However, to best of our knowledge, this is the first study showing the modelling of job crafting behaviours. Our findings are also consistent with Leana et al. (2009) who found that teachers crafted not 
only as an individual, but also as a team. In the latter study, collaborative job crafting was related to job commitment and performance. Collaborative crafting seems a first step to promote job crafting as an organizational practice, as suggested by Kira, van Eijnatten, and Balkin (2010). More specifically, Kira et al. propose that work should be crafted in collaboration between an employee, their colleagues, supervisors and other stakeholders. The aim is to help employees shape their work so that they can simultaneously develop their personal resources and achieve organizational objectives.

We also found evidence for asymmetric relationships between the job crafting dimensions of the actor and the partner. Specifically, if the employee is looking for new interesting projects, the colleague seems to try to learn new things and ask for feedback or advice in order to perform these new projects. This is the only significant asymmetric relationship that we found in this specific sample, but future studies should further explore this possibility, given that asymmetric relationships may exist. Whereas some theories propose the use of behaviour modelling in the workplace as a top-down tactic to facilitate training or newcomer adjustment, job crafting is a bottom-up approach, with management not necessarily being aware of their employees' job crafting behaviours (Wrzesniewski \& Dutton, 2001). For example, in their theory of organizational socialization, Van Maanen and Schein (1979) propose that organizations can use various tactics to facilitate newcomer adjustment. With one of these tactics, called the "serial tactic", the newcomer is socialized by an experienced member of the organization who serves as a role model. Meta-analytic research has shown that this tactic is very effective since it relates to reduced role conflict, reduced role ambiguity, and increased P-E fit, and indirectly predicts job satisfaction, organizational commitment, and, to a lesser extent, job performance (Saks, Uggerslev, \& Fassina, 2007). Our findings suggest that behaviour modelling also happens when management 
does not orchestrate it. Employees who work together seem to influence each other's behaviours that help them to optimize their work environment, and hence continuously improve their P-E fit (Tims \& Bakker, 2010). Colleagues may work together on crafting their jobs and achieve common goals, improving their shared environment. This helps to increase the fit between the person and the environment (P-E fit).

A second contribution of the present study is that we showed that certain forms of job crafting can influence one's own and co-worker's work engagement - an affective, motivational state consisting of vigour, dedication, and absorption (Bakker, 2011). Since work engagement is linked to important organizational outcomes, including in-role performance, organizational citizenship, and financial results (Christian et al., 2011; Xanthopoulou, Bakker, Demerouti \& Schaufeli, 2009), it is a highly relevant outcome.

Consistent with previous research (Bakker et al., 2012; Tims et al., 2012; Petrou et al., 2012), we found a positive relationship between job crafting (in the form of increasing challenge job demands and increasing structural job resources) and one's own work engagement. Job crafting results in work engagement because it changes the job demands and resources such that they are aligned with the preferences and abilities of the employee. Research has indeed confirmed that job resources (but not job demands) act as mediators in this process (see Tims et al., 2013). Does this mean that job crafting is key? Our position is that both employers and employees need to take care of the working environment. When employers take care of job demands and resources, this is a top-down approach, with the aim to take care of the human resources. When employees craft their own jobs, management does not need to be aware of this (Wrzesniewski \& Dutton, 2001). This bottom-up approach can exist next to top-down approaches. Having said all this, some research has shown that autonomy is necessary 
in order for job crafting to take place (Leana et al., 2009; Petrou et al, 2012). This implies that management can facilitate individual employee job crafting behaviours, and recent Dutch research on the effect of job crafting interventions supports this (LeBlanc, Gordon, Demerouti, Bakker, \& Bipp, 2013).

Expanding previous studies, we also found that the actor's job crafting was related to partner's work engagement through partner's job crafting. Results supported this mediating effect for two job crafting behaviours: increasing challenge job demands and increasing structural job resources. This is in agreement with the Job DemandsResources theory (Bakker \& Demerouti, 2008, 2014; Demerouti et al., 2001), which postulates that the mobilization of job resources, such as performance feedback, opportunities for development, and skill variety fosters work engagement, particularly when the job demands are high (Hakanen, Bakker \& Demerouti, 2005). Through vicarious learning, employees find out how to best adjust their work environment to their own abilities and preferences, facilitating person-environment fit (Tims \& Bakker, 2010) and increasing the meaning of their work (Wrzesniewski \& Dutton, 2001). Increasing challenging demands is also related to own and partner's engagement, because such demands stimulate full concentration and promote mastery. Exposure to challenging demands like complex tasks requires a lot of effort, but once completed, these demands also result in considerable rewards - including high-quality performance (Crawford et al., 2010).

Unexpectedly, neither actor nor partner's increasing social job resources was significantly related to partner's work engagement. This dimension refers basically to asking feedback and advice from colleagues and supervisors, as well as mobilizing social support (Tims et al., 2012). In the literature, mixed findings have been found regarding the role of feedback at work, which suggests that feedback may act as a 
double-edged sword. It has been recognized that feedback is a core aspect for promoting motivation and learning in organizations (Erez, 1977). Nevertheless, other research has suggested that there is also a negative side of providing feedback, such as employee's aggressive reactions or burnout when the evaluation is negative (Ilgen \& Davis, 2000; Van Emmerik, Bakker, \& Euwema, 2008). Future research should also take into account whether the employee actually received the expected support or was able to use the feedback or advice in a useful way.

Finally, we also found a negative relationship between actor's decreasing hindrance job demands and partner's work engagement. This relationship was not mediated by partner job crafting, although the results suggested that particularly the crafting of hindrance job demands was imitated. The negative relationship between crafting in the form of decreasing hindrance job demands and work engagement is in line with Petrou et al. (2012), who found in their quantitative diary research that daily reducing job demands was negatively associated with daily work engagement. Similarly, Tims et al. (2012) found a positive relationship between decreasing hindrance job demands and cynicism. Oerlemans and Bakker (2013) have shown that job crafting may in itself be effortful, and thus may undermine engagement. According to Petrou and his colleagues, reducing job demands may also imply that the job becomes less challenging and hence less motivating.

However, the relationship between this job crafting dimension and work engagement is quite complex, and results are mixed. For example, Tims, Bakker, and Derks (2012) did not find a significant relationship between these two variables, whereas in a study among employees working in occupational health services, Tims, Bakker, Derks, and Van Rhenen (2013) found that decreasing hindering job demands was negatively related to vigour but unrelated to dedication, absorption, and 
performance. It is conceivable that decreasing hindrance job demands is more consistently related to fatigue and exhaustion instead of work engagement, since hindrance job demands are basically stressful, not motivating (cf. Crawford et al., 2010). This would also be consistent with JD-R theory, which postulates that (hindrance) job demands are the instigators of a health impairment process that is independent of the motivational process initiated by job resources (cf. Bakker \& Demerouti, 2014; Demerouti et al., 2001). Furthermore, Oerlemans and Bakker (2013) have shown that job crafting may in itself be effortful, and thus may undermine engagement. Clearly, more research is needed to clarify the role of decreasing hindrance job demands as a form of job crafting.

\section{Limitations}

Like any other study, this research has some limitations that should be recognized. First, our design was cross-sectional, which does not allow us to draw any causal conclusions. However, the idea of this study implies a causal chain, between actor and partner's job crafting and work engagement. In fact, according to MacKinnon, Fairchild, and Fritz (2007) definitions of mediation are almost always phrased in causal terms. In this sense, it is important to note that the actor and partner effects in the APIM simply indicate a significant relation, not necessarily a causal one (Cook \& Kenny, 2005). Nevertheless, we based the proposed relations among variables on earlier theoretical theory and empirical evidence. Future longitudinal studies could examine whether there are other, alternative causal relationships (e.g., reversed or reciprocal) among the study variables.

Scholars have not specified the time lag that would be appropriate to assess this process. Tims et al. (2013) use a time-lag of two months to analyse the impact of job 
crafting on job demands, job resources, and well-being and were able to find an increase in job resources and well-being over the course of the study as a result of crafting the job. Previous literature analysing the effects of job demands and resources on work engagement have used different time lags, ranging from one to three years (Hakanen, Schaufeli, \& Ahola, 2008; Mauno, Kinnunen, \& Ruokolainen, 2007; Schaufeli, Bakker, \& van Rhenen, 2009). On the other hand, recent job crafting intervention studies (LeBlanc et al., 2013) have shown that job crafting can affect job demands and resources over the course of several weeks (7-9 weeks). As suggested by de Lange, Taris, Kompier, Houtman, and Bongers (2003), it is difficult to conclude which time lag is appropriate when analysing the effects of work characteristics. We therefore propose, if feasible, to use many follow-up measures both evenly and unevenly spaced.

A second possible limitation of our study is that the majority of the participants was highly educated; almost all of them white collar workers, employed in seven different companies. This, together with the relatively low response rate, may limit the generalizability of our findings to specific groups of workers. Moreover, the sample of respondents was non-random. Three master students who conducted the research approached the companies. Recently, Demerouti and Rispens (2014) have argued and shown that student-recruited samples have several advantages, such as the heterogeneity of the recruited sample, cost reduction, and the opportunity to conduct more elaborated research designs. Although the heterogeneity of the sample and the elaborated design with dyads of colleagues may be considered as strengths of the present study, generalizations of the present findings should be carried out with this limitation in mind.

Third, the companies are located in three countries and we are aware that we have a diverse racial and ethnic group. However, previous studies have shown similar associations between job crafting and different outcomes such as performance, 
engagement or satisfaction, even though they used samples from different countries such as the Netherlands (Bakker, Tims, \& Derks, 2012; Petrou, Demerouti, Peeters, Schaufeli, \& Hetland, 2012; Tims, Bakker, \& Derks, 2013), United Kingdom (McClelland, Leach, Clegg, \& McGowan, 2014), and the US (Leana, Applebaum, \& Shevchuk, 2009; Lyons, 2008). Thus, we do not have reasons to believe that these characteristics have had a major impact on our findings, because some findings are consistent with previous research (the link between job crafting and engagement), while other findings are novel.

Fourth, we do not know how intensive the participants worked together/collaborated. However, please note that a prerequisite to participate was to find a colleague with whom the employee interacted regularly. Previous research has shown that the frequency of communication between co-workers strengthens the crossover of work behaviours such as work engagement (Bakker \& Xanthopoulou, 2009). Future studies should explicitly ask for the number of interactions they have with their colleagues during the working day, as well as other aspects such as the duration of the interaction, the content of the conversation, etc.

Finally, the dyads were most likely part of work teams, but unfortunately, we did not have the data to examine this. Future studies could try to replicate the present findings by investigating the modelling of job crafting behaviours in the context of teams. Indeed, we focussed on job crafting as an individual behaviour, but common environmental features may trigger identical job crafting behaviours shown by two employees in one team. Future research should address this issue by analysing "collaborative job crafting", that is, the extent to which employees craft their jobs to meet common goals. Although this was beyond the scope of this study, there is 
evidence that job crafting may be also performed at the team level (Tims, Bakker, Derks, \& van Rhenen, 2013).

\section{Implications}

Despite these limitations, the present findings may have important implications for both future research and practice. First, from a theoretical point of view, the modelling of job crafting behaviours found in this study indicates that job crafting is not just an individual-level phenomenon. Our findings suggest that job crafting initiates an interpersonal process, and that theoretical models of job crafting should incorporate social elements of the work environment, including the role of colleagues or the work team. Our study responds to the call for research on organizational phenomena from an interpersonal, dyadic approach (Ferris et al., 2009). Second, as Manz and Sims (1981) pointed out more than three decades ago, managers also have a unique opportunity to influence employee behaviour because of their reward power. In addition to using rewards in the typical way to directly influence follower performance, managers may also create effective role models by publically rewarding an employee in such a way that other employees are aware of the reward. For example, the manager may give positive feedback publicly, which would be a form of reward. This could encourage employees to ask the supervisor to coach them and broaden communication channels (that is, to increase social job resources).

Moreover, managers may also directly stimulate employee job crafting behaviours, for example through job crafting training, or by simply giving enough leeway to employees to engage in job crafting. Particularly opportunities to craft challenge job demands and structural job resources may facilitate P-E fit and employee work engagement. 


\section{Funding}

This research received no specific grant from any funding agency in the public, commercial, or not-for-profit sectors.

\section{References}

Bakker, A. B. (2011). An evidence-based model of work engagement. Current Directions in Psychological Science, 20, 265-269.

Bakker, A. B., \& Demerouti, E. (2008). Towards a model of work engagement. Career Development International, 13, 209-223.

Bakker, A. B., \& Demerouti, E. (2014). Job Demands-Resources theory. In C. Cooper, \& P. Chen (Eds.), Wellbeing: A complete reference guide (pp. 37-64). Chichester, UK: Wiley-Blackwell.

Bakker, A., Demerouti, E., \& Schaufeli, W. B. (2005). The crossover of burnout and work engagement among working couples. Human Relations, 58, 661-689.

Bakker, A. B., \& Sanz-Vergel, A. I. (2013). Weekly work engagement and flourishing: The role of hindrance and challenge demands. Journal of Vocational Behavior, 83, 397-409.

Bakker, A. B., Tims, M., \& Derks, D. (2012). Proactive personality and performance: The role of job crafting and work engagement. Human Relations, 65, 13591378.

Bakker, A. B., \& Xanthopoulou, D. (2009). The crossover of daily work engagement: Test of an actor-partner interdependence model. Journal of Applied Psychology, 94, 1562-1571.

Bandura, A. (1977). Social learning theory. Englewood Cliffs, N.J.: Prentice-Hall. Bandura, A. (1997). Self-efficacy: The exercise of control. New York: Freeman. 
Brass, D. J., \& Burkhardt, M. E. (1993). Potential power and power use: An investigation of structure and behavior. Academy of Management Journal, 36, 441-470.

Buss, D. M. (1987). Selection, evocation, and manipulation. Journal of Personality and Social Psychology, 53, 1214-1221.

Campion, M. A. (1988). Interdisciplinary approaches to job design: A constructive replication with extensions. Journal of Applied Psychology, 73, 467-481.

Christian, M. S., Garza, A. S., \& Slaughter, J. E. (2011). Work engagement: A quantitative review and test of its relations with task and contextual performance. Personnel Psychology, 64, 89-136.

Cook, W., \& Kenny, D. A. (2005). The Actor-Partner Interdependence Model: A model of bidirectional effects in developmental studies. International Journal of Behavioral Development, 29, 101-109.

Crawford, E. R., LePine, J. A., \& Rich, B. L. (2010). Linking job demands and resources to employee engagement and burnout: A theoretical extension and meta-analytic test. Journal of Applied Psychology, 95, 834-848.

de Lange, A. H., Taris, T. W., Kompier, M. A. J., Houtman, I. L. D., \& Bongers, P. M. (2003). "The very best of the millennium": Longitudinal research and the Demand-Control-(Support) Model. Journal of Occupational Health Psychology, 8, 282-305.

Demerouti E., Bakker, A. B., Nachreiner, F., \& Schaufeli, W. B. (2001). The Job Demands - Resources model of burnout. Journal of Applied Psychology, 86, 499-512. 
Demerouti, E., \& Rispens, S. (2014). Improving the image of student-recruited samples: A commentary. Journal of Occupational and Organizational Psychology, 87, $34-41$.

Erez, M. (1977). Feedback: A necessary condition for the goal setting - performance relationship. Journal of Applied Psychology, 62, 624-627.

Ferris, G. R., Liden, R. C., Munyon, T. P., Summers, J. K., Basik, K. J., \& Buckley, M. R. (2009). Relationships at work: Toward a multidimensional conceptualization of dyadic work relationships. Journal of Management, 35, 1379-1403.

Hackman, J. R., \& Oldham, G. R. (1980). Work redesign. Reading, MA: AddisonWesley.

Hakanen, J.J., Bakker, A.B., \& Demerouti, E. (2005). How dentists cope with their job demands and stay engaged: The moderating role of job resources. European Journal of Oral Sciences, 113, 479-487.

Hakanen, J. J., Schaufeli, W.B., \& Ahola, K. (2008). The Job Demands-Resources model: A three-year cross-lagged study of burnout, depression, commitment and work engagement. Work \& Stress, 22, 224-241.

Hox, J. J. (2002). Multilevel analysis: Techniques and applications. Mahwah, NJ: Erlbaum.

Ilgen, D. R., \& Davis, C. R. (2000). Bearing bad news: Reactions to negative performance feedback. Applied Psychology: An International Review, 49, 550565.

Kashy, D. A., \& Kenny, D. A. (2000). The analysis of data from dyads and groups. In H. T. Reis \& C. M. Judd (Eds.), Handbook of research methods in social psychology (451-477). New York: Cambridge University Press. 
Kenny, D. A., Kashy, D. A., \& Cook, W. L. (2006). Dyadic data analysis. New York: The Guilford Press.

Kira, M., van Eijnatten, F. M., \& Balkin D. B. (2010), Crafting sustainable work: Development of personal resources. Journal of Organizational Change Management, 23, 5, 616-632.

Laurence, G. A. (2010). Workaholism and expansion and contraction oriented job crafting: The moderating effects of individual and contextual factors. Unpublished doctoral dissertation. Syracuse University.

Leana, C., Appelbaum, E., \& Shevchuk, I. (2009). Work process and quality of care in early childhood education: The role of job crafting. Academy of Management Journal, 52, 1169-1192.

LeBlanc, P., Gordon, H., Demerouti, E., Bakker, A.B., \& Bipp, T. (2013). Job crafting, well-being and performance of Dutch health care providers: Results of two intervention studies. Oral presentation at the European Congress of Psychology, Stockholm, 11 July 2013.

Lyons, P. (2008). The crafting of jobs and individual differences. Journal of Business and Psychology, 23, 25-36.

MacKinnon, D. P., Fairchild, A. J., \& Fritz, M. S. (2007). Mediation analysis. Annual Review of Psychology, 58, 593-614.

Manz, C. C., \& Sims, H. P. (1981). Vicarious learning: The influence of modeling on organizational behavior. Academy of Management Review, 6, 105-113.

Mathieu, J. E., \& Taylor, S. R. (2006). Clarifying conditions and decision points for mediational type inferences in organizational behavior. Journal of Organizational Behavior, 27, 1031-1056. 
Mauno, S., Kinnunen, U., \& Ruokolainen, M. (2007). Job demands and resources as antecedents of work engagement: A longitudinal study. Journal of Vocational Behavior, 70,149-171.

McClelland, G. P., Leach, D. J., Clegg, C. W., \& McGowan, I. (2014). Collaborative crafting in call centre teams. Journal of Occupational and Organizational Psychology. DOI: 10.1111/joop.12058.

Oldham, G. R., \& Hackman, J. R. (2010). Not what it was and not what it will be: The future of job design research. Journal of Organizational Behavior, 31, 463-479.

Oerlemans, W., \& Bakker, A. B. (2013). How daily job crafting increases momentary work engagement: A day reconstruction study. Oral presentation at the $16^{\text {th }}$ conference of the European Association of Work \& Organizational Psychology. Munster, May 22-25, 2013.

Petrou, P., Demerouti, E., Peeters, M. C. W., Schaufeli, W. B., \& Hetland, J. (2012). Crafting a job on a daily basis: Contextual correlates and the link to work engagement. Journal of Organizational Behavior, 33, 1120-1141.

Petrou, P., Demerouti, E., \& Schaufeli, W. B. (in press). Crafting the change: The role of employee job crafting behaviors for successful organizational change. Journal of Occupational Health Psychology.

Postmes, T., Spears, R., \& Lea, M. (2000). The formation of group norms in computer mediated communication. Human Communication Research, 26, 341-371.

Rasbash, J., Browne, W., Healy, M., Cameron, B., \& Charlton, C. (2002). MLwiN (Version 1.10.006): Interactive software for multilevel analysis. Centre for Multilevel Modelling, Institute of Education, University of London. 
Saks, A. M., Uggerslev, K. L., \& Fassina, N. E. (2007). Socialization tactics and newcomer adjustment: A meta-analytic review and test of a model. Journal of Vocational Behavior, 70, 413-446.

Salancik, G. R., \& Pfeffer, J. (1978) A social information processing approach to job attitudes and task design. Administrative Science Quarterly, 23, 224-253.

Sanz-Vergel, A. I., Rodríguez-Muñoz, A., Bakker, A. B., \& Demerouti, E. (2012). The daily spillover and crossover of emotional labor: Faking emotions at work and at home. Journal of Vocational Behavior, 81, 209-217.

Schaufeli, W. B., Bakker, A. B., \& Salanova, M. (2006). The measurement of work engagement with a short questionnaire. Educational and Psychological Measurement, 66, 701-716.

Schaufeli, W. B., Bakker, A. B., \& Van Rhenen, W. (2009). How changes in job demands and resources predict burnout, work engagement, and sickness absenteeism. Journal of Organizational Behavior, 30, 893-917.

Schneider, B. (1987). The people make the place. Personnel Psychology, 40, 437-454.

Sobel, M. E. (1982). Asymptotic confidence intervals for indirect effects in structural equation models. In S. Leinhardt (Ed.), Sociological methodology (pp. 290312). Washington, DC: American Sociological Association.

Spybrook, J., Raudenbush, S. W., Liu, X. F., Congdon, R., \& Martínez, A. (2008). Optimal design for longitudinal and multilevel research: Documentation for the “Optimal Design” software (Version 1.76) [Software manual]. Ann Arbor: University of Michigan.

Tims, M., \& Bakker, A. B. (2010). Job crafting: Towards a new model of individual job redesign. South African Journal of Industrial Psychology, 36, 1-9.

Tims, M., Bakker, A. B., \& Derks, D. (2012). Development and validation of the job 
crafting scale. Journal of Vocational Behavior, 80, 173-186.

Tims, M., Bakker, A. B., \& Derks, D. (2013). The impact of job crafting on job demands, job resources, and well-being. Journal of Occupational Health Psychology, 18, 230-240.

Tims, M., Bakker, A.B., Derks, D., \& Van Rhenen, W. (2013). Job crafting at the team and individual level: Implications for work engagement and performance. Group and Organization Management, 38, 427-454.

Van den Broeck, A., de Cuyper, N., de Witte, H., \& Vansteenkiste, M. (2010). Not all job demands are equal: Differentiating job hindrances and job challenges in the Job Demands-Resources model. European Journal of Work and Organizational Psychology, 19, 735-759.

Van den Broeck, A., Vansteenkiste, M., De Witte, H., \& Lens, W. (2008). Explaining the relationships between job characteristics, burnout, and engagement: The role of basic psychological need satisfaction. Work \& Stress, 22, 277-294.

Van Emmerik, I. J. H., Bakker, A. B., \& Euwema, M. C. (2008). What happens after the developmental assessment center? Employees' reactions to unfavorable performance feedback. Journal of Management Development, 27, 513-527.

Van Maanen, J., \& Schein, E. H. (1979). Toward a theory of organizational socialization. In B. M. Staw (Ed.), Research in Organizational Behavior (Vol. 1, pp. 209-264). Greenwich, CT: JAI Press.

Wrzesniewski, A., \& Dutton, J. E. (2001). Crafting a job: Revisioning employees as active crafters of their work. Academy of Management Review, 26, 179-201.

Xanthopoulou, D., Bakker, A.B., Demerouti, E., \& Schaufeli, W.B. (2009). Work engagement and financial returns: A diary study on the role of job and personal 
resources. Journal of Occupational and Organizational Psychology, 82, 183200.

Zhou, J. (2003). When the presence of creative coworkers is related to creativity: Role of supervisor close monitoring, developmental feedback, and creative personality. Journal of Applied Psychology, 88, 413-422. 
Table 1. Mean, standard deviations, and correlations ( $N=103$ dyads, $N=206$ individuals)

\begin{tabular}{|c|c|c|c|c|c|c|c|c|c|c|c|}
\hline Variable & $\mathrm{M}(\mathrm{SD})$ & 1 & 2 & 3 & 4 & 5 & 6 & 7 & 8 & 9 & 10 \\
\hline 1. Increasing structural job resources, actor & $4.21(.64)$ & --- & & & & & & & & & \\
\hline 2. Increasing structural job resources, partner & $4.21(.64)$ & $.35^{* *}$ & --- & & & & & & & & \\
\hline 3. Increasing social job resources, actor & $3.41(.80)$ & $.27 * *$ & $.14 *$ & --- & & & & & & & \\
\hline 4. Increasing social job resources, partner & $3.41(.80)$ & $.14^{*}$ & $.27^{* *}$ & $.30^{* *}$ & --- & & & & & & \\
\hline 5. Increasing challenge job demands, actor & $3.59(.81)$ & $.49 * *$ & $.32 * *$ & $.37 * *$ & $.29 * *$ & --- & & & & & \\
\hline 6. Increasing challenge job demands, partner & $3.59(.81)$ & $.32 * *$ & $.49 * *$ & $.29 * *$ & $.37 * *$ & $.45^{* *}$ & --- & & & & \\
\hline 7. Decreasing hindrance job demands, actor & $3.45(.67)$ & .13 & .06 & .12 & $.14^{*}$ & .03 & .08 & --- & & & \\
\hline 8. Decreasing hindrance job demands, partner & $3.45(.67)$ & .06 & .13 & $.14 *$ & .12 & .08 & .03 & $.51^{* *}$ & --- & & \\
\hline 9. Work engagement, actor & $4.70(.99)$ & $.57 * *$ & $.28 * *$ & $.26^{* *}$ & $.16^{*}$ & $.49 * *$ & $.31^{* *}$ & -.07 & -.12 & --- & \\
\hline 10. Work engagement, partner & $4.70(.99)$ & $.28 * *$ & $.57^{* *}$ & $.16^{*}$ & $.26^{* *}$ & $.31^{* *}$ & $.49^{* *}$ & -.12 & -.07 & $.40^{* *}$ & --- \\
\hline
\end{tabular}

$* p<.05, * * p<.01$. 
Table 2. Multilevel estimates for models predicting work engagement of the partner $(\mathrm{N}=103 \mathrm{dyads}, \mathrm{N}=206$ individuals $)$

\begin{tabular}{|c|c|c|c|c|c|c|c|c|c|c|c|c|}
\hline \multirow{2}{*}{ Variable } & \multicolumn{3}{|c|}{ Null model } & \multicolumn{3}{|c|}{ Model 1} & \multicolumn{3}{|c|}{ Model 2} & \multicolumn{3}{|c|}{ Model 3} \\
\hline & Estimate & SE & $\mathrm{t}$ & Estimate & SE & $\mathrm{t}$ & Estimate & SE & $\mathrm{t}$ & Estimate & SE & $\mathrm{t}$ \\
\hline Intercept & 4.707 & 0.082 & $57.4^{* * * *}$ & 4.707 & 0.080 & $58.8^{* * *}$ & 4.707 & 0.063 & $74.7 * * *$ & 4.707 & 0.057 & $82.5^{* * *}$ \\
\hline Gender & & & & 0.146 & 0.141 & 1.03 & 0.134 & 0.133 & 1.00 & 0.075 & 0.112 & 0.66 \\
\hline Increasing structural job resources (actor) & & & & & & & 0.270 & 0.118 & $2.28 *$ & 0.065 & 0.097 & 0.67 \\
\hline Increasing social job resources (actor) & & & & & & & 0.070 & 0.088 & 0.79 & 0.023 & 0.074 & 0.31 \\
\hline Increasing challenge job demands (actor) & & & & & & & 0.258 & 0.094 & $2.74 * *$ & 0.045 & 0.079 & 0.56 \\
\hline Decreasing hindrance job demands (actor) & & & & & & & -0.222 & 0.091 & $-2.43^{* *}$ & -0.207 & 0.087 & $-2.37 * *$ \\
\hline Increasing structural job resources (partner) & & & & & & & & & & 0.664 & 0.095 & $6.98 * * *$ \\
\hline Increasing social job resources (partner) & & & & & & & & & & 0.065 & 0.074 & 0.87 \\
\hline Increasing challenge job demands (partner) & & & & & & & & & & 0.298 & 0.079 & $3.77 * * *$ \\
\hline Decreasing hindrance job demands (partner) & & & & & & & & & & -0.118 & 0.087 & 0.13 \\
\hline$-2 \times \log (\mathrm{lh})$ & & 562.594 & & & 561.618 & & & 545.707 & & & 457.657 & \\
\hline Difference of $-2 X \log$ & & & & & 1.32 & & & $15.91 * *$ & & & $88.05 * * *$ & \\
\hline df & & & & & 1 & & & 4 & & & 4 & \\
\hline Level 1 intercept variance (SE) & & $0.587(0.082)$ & & & $0.602(0.084)$ & & & $0.828(0.082)$ & & & $0.441(0.061)$ & \\
\hline Level 2 intercept variance (SE) & & $0.394(0.104)$ & & & $0.364(0.102)$ & & & $0.000(0.000)$ & & & $0.110(0.055)$ & \\
\hline
\end{tabular}

$* p<.05, * * p<.01, * * * p<.001$ 


\section{Author biographies}

Prof. Arnold B. Bakker is professor of Work and Organizational Psychology at Erasmus University Rotterdam, The Netherlands. He is also Adjunct professor at Lingnan University, Hong Kong, and Distinguished visiting professor at the University of Johannesburg, South Africa. Bakker is Past President of the European Association of Work and Organizational Psychology. He is particularly interested in positive organizational behavior and happiness economics, including work engagement, happiness, JD-R theory, job crafting, creativity, and job performance. Bakker publishes regularly in the main journals in the field, including Journal of Organizational Behavior and Journal of Vocational Behavior. He is editor of "Current issues in Work and Organizational Psychology” (Psychology Press), and “Advances in Positive Organizational Psychology" (Emerald). More information: www.arnoldbakker.com or www.profarnoldbakker.com. Email: bakker@fsw.eur.nl

Alfredo Rodríguez Muñoz is Assistant Professor at the Department of Social Psychology at Complutense University of Madrid, Spain. His current research interests focus on organizational and health psychology, bullying at work, and employee well-being. His work has been published in journals such as Work \& Stress, Journal of Occupational and Organizational Psychology, European Journal of Work and Organizational Psychology, and Journal of Vocational Behavior. Email: alfredo.rodriguez@psi.ucm.es

Ana Isabel Sanz Vergel is a Lecturer in Organisational Behaviour at Norwich Business School, University of East Anglia. Her research interests are related to the field of work and organizational psychology, occupational health, and employee well-being, including topics such as daily recovery from stress, work-family conflict, and crossover of work- 
related experiences. Her research has been published in journals such as Journal of Vocational Behavior, Human Relations, Journal of Occupational and Organizational Psychology, and Journal of Occupational Health Psychology. Email: a.sanzvergel@uea.ac.uk

\section{Corresponding author:}

Arnold B Bakker

Dept of Work and Org. Psychology

Erasmus University Rotterdam

PO Box 1738, T12-47 Rotterdam 3000 DR

The Netherlands

T: +31(0)10408 8853

F: +31(0)104089009

bakker@fsw.eur.nl

\section{Other author(s):}

Alfredo Rodriguez-Munoz,

Complutense University of Madrid

Madrid

Spain

alfredo.rodriguez@psi.ucm.es 
Ana Isabel Sanz Vergel,

Norwich Business School

University of East Anglia

Norwich

United Kingdom

A.Sanz-Vergel@uea.ac.uk 